\title{
Obtaining of Sol-Gel Ketorolac-Silica Nanoparticles: Characterization and Drug Release Kinetics
}

\author{
T. M. López Goerne, ${ }^{1,2,3}$ M. G. López García, ${ }^{1,2}$ G. Rodríguez Grada, ${ }^{1,2}$ I. Ortiz Pérez, \\ E. Gómez López, ${ }^{4}$ and M. A. Alvarez Lemus ${ }^{2}$ \\ ${ }^{1}$ Laboratorio de Nanotecnología y Nanomedicina, Departamento de Atención a la Salud, Universidad Autónoma \\ Metropolitana Xochimilco, Calzada del Hueso 1100, Col. Villa Quietud, Delegación Coyoacán, 04960 México, DF, Mexico \\ ${ }^{2}$ Laboratorio de Nanotecnología, Instituto Nacional de Neurología y Neurocirugía "Manuel Velasco Suárez", Avenida Insurgentes \\ sur 3877, Col. La Fama, 14269 Tlalpan, DF, Mexico \\ ${ }^{3}$ Department of Chemical and Biomolecular Engineering, Tulane University, New Orleans, LA 70118, USA \\ ${ }^{4}$ Facultad de Ciencias, Universidad Nacional Autónoma de México, Avenida Universidad 3000, Circuito Exterior \\ S/N Delegación Coyoacán, Ciudad Universitaria, 04510 México, DF, Mexico
}

Correspondence should be addressed to M. A. Alvarez Lemus; maalvarez@innn.edu.mx

Received 24 August 2012; Accepted 1 November 2012

Academic Editor: Yan-Yan Song

Copyright (C) 2013 T. M. López Goerne et al. This is an open access article distributed under the Creative Commons Attribution License, which permits unrestricted use, distribution, and reproduction in any medium, provided the original work is properly cited.

\begin{abstract}
Nonsteroidal anti-inflammatory drugs (NSAIDs) are among most commonly prescribed medications worldwide. NSAIDs play an important role due to their pronounced analgesic potency, anti-inflammatory effects, and lesser side effects compared to opioids. However, adverse effects including gastrointestinal and cardiovascular effects seriously complicate their prolonged use. In the present work we prepare $\mathrm{SiO}_{2}$-based nanoparticles with ketorolac, for controlled release proposes. The nanomaterials were prepared by the sol-gel technology at acidic conditions and two different water/alcoxide ratios were used. FTIR spectroscopy was performed in order to characterize the solids and drug- $\mathrm{SiO}_{2}$ interactions. Thermal analysis and nitrogen adsorption isotherms showed thermal stability of the drug and confirmed the presence of particles with high surface area. Transmission electron micrographies of the samples showed the nanosize particles $(20 \mathrm{~nm})$ forming aggregates. Drug release profiles were collected by means of UV-Vis spectroscopy and kinetic analysis was developed. Release data were fitted and 1:8 sample showed a sustained release over ten hours; $90 \%$ of the drug was delivered at the end of the time.
\end{abstract}

\section{Introduction}

Nanotechnology drug delivery, diagnosis, and drug development represent the change in medicine in 21st century. This field is an area that will produce significant results, in this way the drug is controlled during days or even weeks, depending on the disease to treat [1]. Nanoparticulate drug delivery vehicles can be organic or inorganic solids but biocompatible and nontoxic. These novel systems allow drug absorption in a controlled way and with less adverse side effects [2].

Nonsteroidal anti-inflammatory drugs (NSAIDs) are among most commonly prescribed medications worldwide [3]. Approximately $20 \%$ of people older than 65 years have been prescribed NSAIDs [4]. In acute pain as headache, stomach ache, or flu, NSAIDs play an important role due to their pronounced analgesic potency, anti-inflammatory effects, and lesser side effects compared to opioids $[5,6]$. However, adverse effects including gastrointestinal (GI) and cardiovascular (CV) seriously complicate their prolonged use [7].

Ketorolac tromethamine (KT), Figure 1, is a pyrrolizine carboxylic acid derivative of NSAIDs with potent analgesic and moderate anti-inflammatory activity, a relatively favorable therapeutic agent for the management of moderate to severe pain $[8,9]$. The beneficial effects of KT are probably due to its ability to block prostaglandin synthesis by preventing the conversion of arachidonic acid to the endoperoxides [10]. 


$$
\mathrm{Si}\left(\mathrm{OC}_{2} \mathrm{H}_{5}\right)_{4}+x \mathrm{H}_{2} \mathrm{O} \stackrel{\mathrm{C}_{2} \mathrm{H}_{5} \mathrm{OH}}{\longrightarrow} \mathrm{Si}\left(\mathrm{OC}_{2} \mathrm{H}_{5}\right)_{4-x}(\mathrm{OH})_{x}+x \mathrm{C}_{2} \mathrm{H}_{5} \mathrm{OH}
$$

SCHEME 1: Hydrolysis of TEOS.

For instance, weight by weight $\mathrm{KT}$ proved to be 50 times more potent than naproxen in analgesia models but only 3 times more potent in inflammation models [11]. This remarkable dissociation between analgesic and antiinflammatory effects provided the basis for the development of the drug as excellent anti-inflammatory and analgesic. In clinical settings however ketorolac has been involved as a contributing cause of increased postoperative bleeding, renal failure, and gastritis; the severity of these side effects is probably dose related [12].

For these reasons, many attempts to develop novel formulation strategies to deliver KT had been made. Sinha and Trehan [13] prepared drug-loaded polycaprolactone and poly lactic-co-glycolic acid microspheres, Rokhade et al. [14] developed semi-interpenetrating polymer network microspheres of gelatin and sodium carboxymethyl cellulose, and recently, Genc and Jalvand [15] produced controlled release hydrophilic matrix tablets.

The use of mesoporous silica nanoparticles offers a suitable method to deliver drugs toward specific tissues or cells depending on drug properties [16]. Sol-gel inorganic nanoparticles exhibit significantly higher surface area and porosity [17] which means more available surface to place molecules of interest. One of the main advantages of sol-gel process is that materials exhibit special features like highly hydroxylated surface which has demonstrated to be one facile method to achieve functionalized surfaces. Additionally, solgel process provides the opportunity to release a great variety of biomolecules, medicines, or compounds from the oxide structure, while functionalization or surface modification is relatively easy.

Sol-gel chemistry uses neutral, acidic, or basic conditions to achieve hydrolysis and condensation of numerous silane monomers $\equiv \mathrm{Si}-\mathrm{O}$ and $\mathrm{O}-\mathrm{Si}-\mathrm{OH}$ (Scheme 1) [17-20].

At present, a great deal of emphasis is being placed on the development of controlled or sustained release forms for the drug as this would help in achieving the required therapeutic efficacy and better tolerance. The main goal of this study was to develop ketorolac silica reservoir (ketorolac-SiO ${ }_{2}$ ) delivery system using sol-gel method.

\section{Experimental}

2.1. Materials. Tetraethoxysilane (TEOS) 98\%, was purchased from Sigma-Aldrich. Ketorolac tromethamine $\left(\mathrm{C}_{15} \mathrm{H}_{13} \mathrm{NO}_{3}, \mathrm{MW} 255.27 \mathrm{~g} / \mathrm{mol}\right)$ by Lyomont laboratories was also purchased, all organic solvents were purchased from Sigma-Aldrich.

2.2. Preparation of Reservoir. Silica reservoir was made by sol-gel process at room temperature using two water alkoxide molar ratios 1:8 and 1:4; the same ethanol:alkoxide ratios were used. Preparation was as follows: appropriated amounts of water and ethanol were placed and mixed in a three neck round-bottom flask. Then $18.5 \mathrm{~mL}$ of TEOS was dropwise simultaneously but in a different neck with the drug $\left(6 \mathrm{mg} / \mathrm{gSiO}_{2}\right)$. The mixture was left under stirring for 14-21 days. Other $\mathrm{SiO}_{2}$ nanoparticles were prepared under the same conditions but without analgesic. Then, dried material was crushed in an agata mortar.

2.3. Characterization. Infrared absorption spectra, of the nanomaterials were obtained on IRAffinity-1 FTIR system. A tablet with the different samples (5\%wt) was pressed together with $95 \%$ wt of $\mathrm{KBr}\left(2000\right.$ ton/in $\left.{ }^{2}\right)$.

Thermograms were carried out using a Simultaneous Thermal Analyzer STA i-1000. Samples were placed in a platinum pan and heated at a rate of $10^{\circ} \mathrm{C} / \mathrm{min}$, in $\mathrm{N}_{2}$ atmosphere from room temperature to $800^{\circ} \mathrm{C}$.

2.4. Morphology Study. High-resolution transmission electron microscopy (TEM) images were obtained using a TEM microscope, JEOL JEM-2100F, operated at $200 \mathrm{kV}$ and equipped with an energy dispersive spectroscopic (EDS) microanalysis system (Oxford). The images were obtained using a Gatan Orius camera.

2.5. Nitrogen Adsorption Measurements. Nitrogen adsorption-desorption isotherms were obtained using a Micromeritics Belsorp II, Bell Japan Inc The Brunauer-EmmettTeller (BET) method was used to calculate specific surface areas $\left(S_{\mathrm{BET}}\right)$. Pore volumes and pore size distributions were obtained using $\mathrm{BJH}$ method.

2.6. Controlled Drug Release. A tablet made of each Ketorolac- $\mathrm{SiO}_{2}$ nanomaterial (1:4 and 1:8 ratios) was placed into a glass with deionized water $(50-75 \mathrm{~mL})$. Sampling was performed at different periods of time over a total of 200 hours. Analysis was performed using ultraviolet spectroscopy (Cary-1 UV-visible, Varian) by following the increase in main absorption bands reported for ketorolac. After measurements, samples were returned to the glass to maintain constant volume. A calibration curve was performed and absorbance spectra were collected. In order to calculate drug concentration Lambert-Beer law was used. Drug release curves were obtained by plotting cumulative drug concentration versus time. Determinations were made by duplicate.

2.7. Applied Methods to Compare Drug Release Profiles. Ketorolac release kinetics from each nanomaterial was analyzed by several mathematical models. Depending on these estimations, suitable mathematical models to describe dissolution profiles were determined. The following plots were made: dissolution \% drug release versus time (zero-order kinetic model); Ln dissolution \% drug remaining versus time (first-order kinetic model); dissolution \% drug release versus square root of time (Higuchi model); cube root of drug \% remaining in matrix versus time (Hixson-Crowell cube root law); and dissolution \% drug release versus time (hyperbola). 


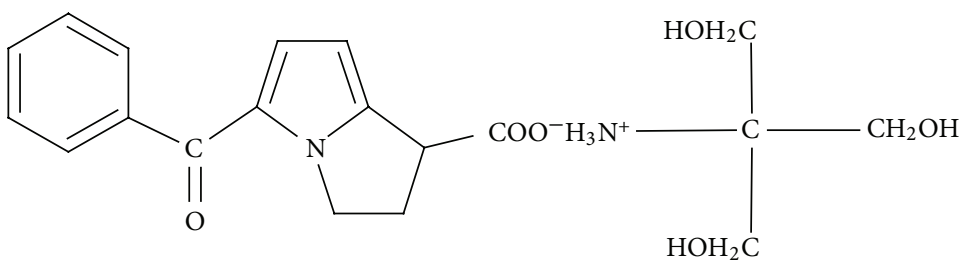

Figure 1: Structure of Ketorolac tromethamine.

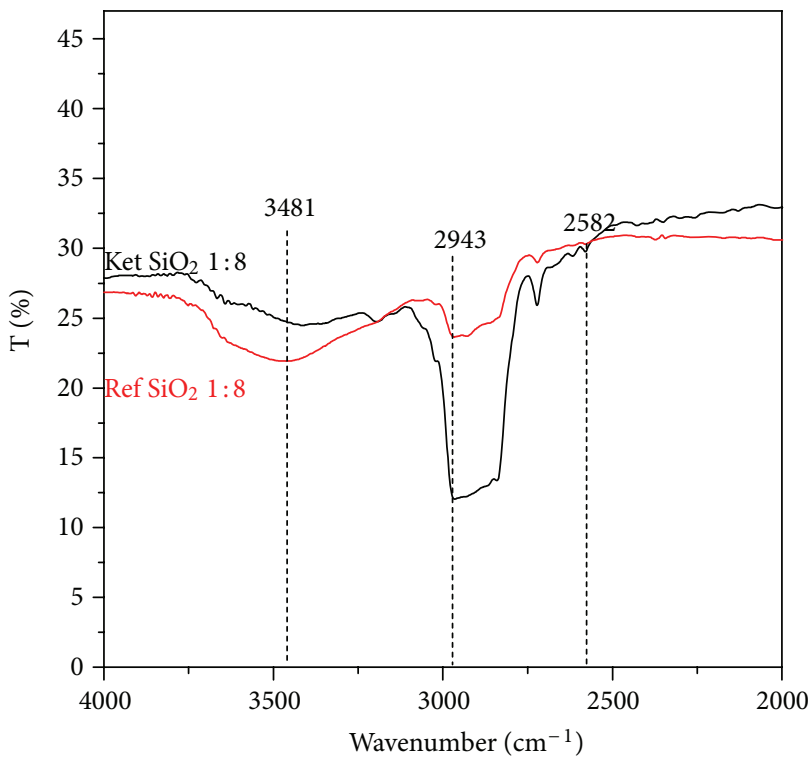

(a)

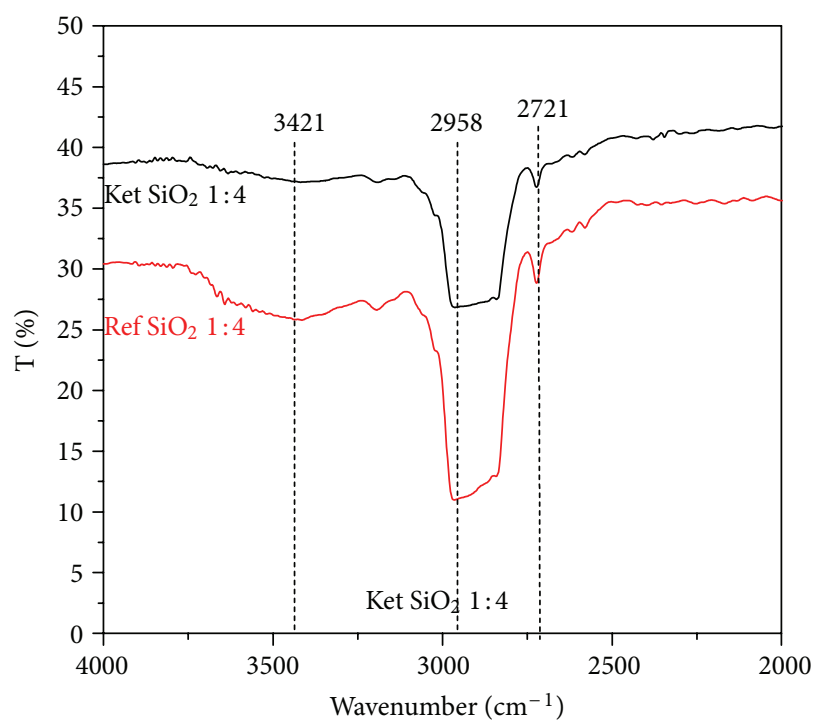

(c)

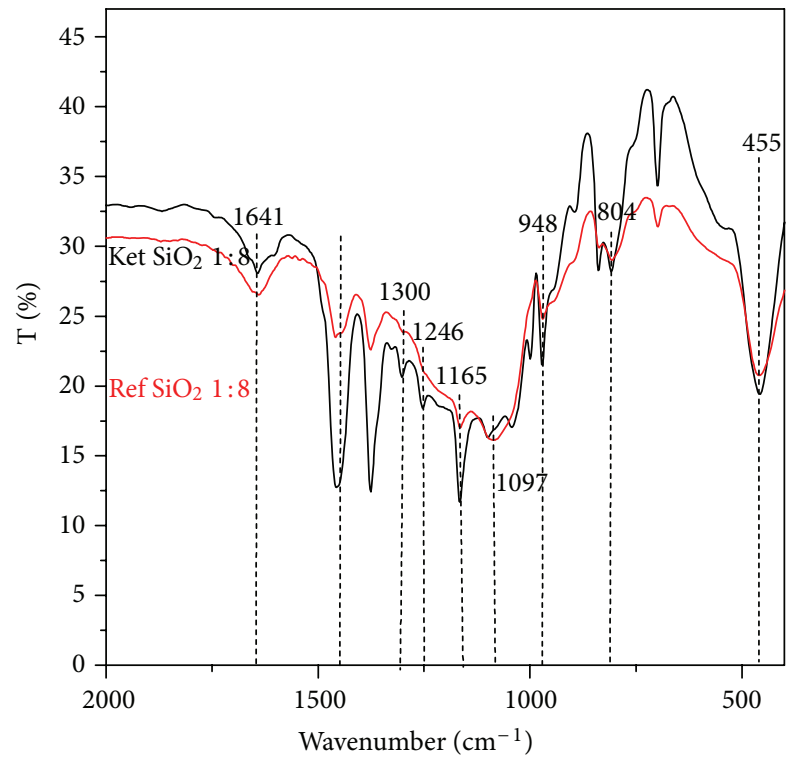

(b)

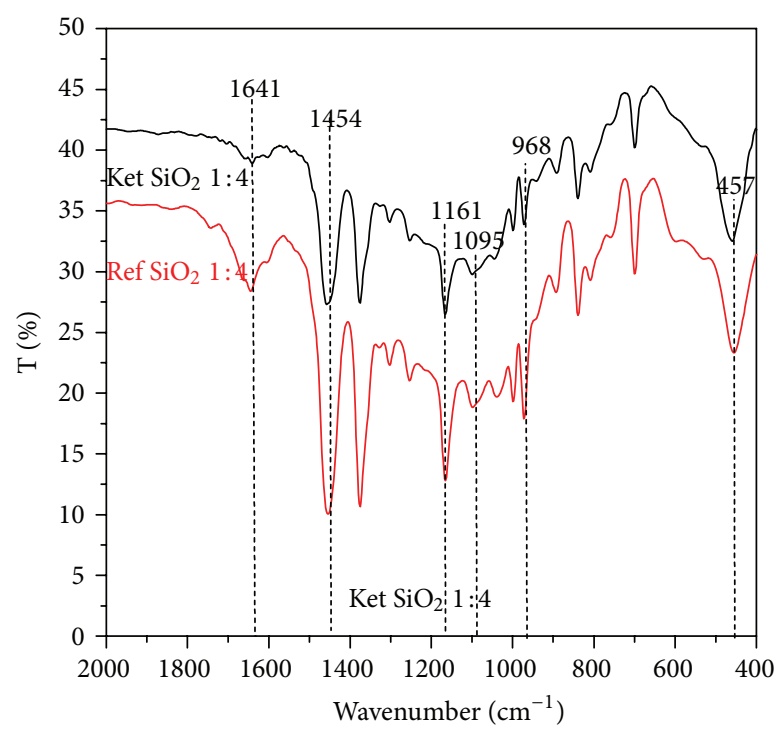

(d)

FIGURE 2: IR spectra of (a) and (b) 1:8 ratio; (c) and (d) $1: 4$ ratio $\mathrm{SiO}_{2}$ based materials.

\section{Results and Discussion}

3.1. Characterization. Figure 2 shows the most distinctive infrared absorption bands of silica for both ratios. In the $3500-3200 \mathrm{~cm}^{-1}$ region, the $\mathrm{O}-\mathrm{H}$ stretching band due to residual water and $\mathrm{Si}-\mathrm{OH}$ vibration was observed, this is typical in sol-gel materials, and the presence of $\mathrm{O}-\mathrm{H}$ from methanol groups of the drug contributes to this band. Presence of adsorbed water is confirmed by the appearance of a band around $1641 \mathrm{~cm}^{-1}$ in all the samples. The signals 
centered at 455 and $457 \mathrm{~cm}^{-1}$ are related with the $\mathrm{Si}-\mathrm{O}-$ $\mathrm{Si}$ bond deformation. The band around $1100 \mathrm{~cm}^{-1}$ is split into two bands at 1165 and $1097 \mathrm{~cm}^{-1}$ for the $1: 8$ material and at 1161 and $1095 \mathrm{~cm}^{-1}$ for 1:4 ratio; these correspond to stretching vibrations of $\mathrm{Si}-\mathrm{O}-\mathrm{Si}$ bonds. At 804 and $810 \mathrm{~cm}^{-1}$ we observed of $\mathrm{Si}-\mathrm{O}^{-}$flexion vibrations for $1: 8$ and 1:4 ratios, respectively. $\mathrm{Si}-\mathrm{OH}$ stretching bands were observed at 948 and $968 \mathrm{~cm}^{-1}$, these results are similar to those reported by Gonzáles et al. [18] and Kalampounias [21], no absorption bands of Ketorolac can be clearly assigned, since most of the signals due to the bonds of the drug are overlapped white silica bands. However some features are slightly distinguished; a more intense band was observed at $1450 \mathrm{~cm}^{-1}$ for Ketorolac-SiO 2 1:8 and at $1454 \mathrm{~cm}^{-1}$ for Ketorolac- $\mathrm{SiO}_{2} 1: 4$. In this region $\mathrm{C}=\mathrm{C}$ ring antisymmetric elongation can be detected, this band is less intense in both silica references due to in those samples there still remains residual ethanol from the synthesis, so the band we observed corresponds to $\mathrm{O}-\mathrm{H}$ deformation.

TGA curves are shown in Figure 3. Weight loss was very similar for all samples. For 1:8 ratio, the first loss was about $5 \%$ for Ketorolac- $\mathrm{SiO}_{2}$ and ca. $8 \%$ for the reference around from room temperature to $150^{\circ} \mathrm{C}$. This first gradual loss is associated with residual ethanol of the synthesis, and dehydratation from both silica and the drug [22]. A second loss was recorded around $168^{\circ} \mathrm{C}$ (ca. $3 \%$ ) in Ketorola- $\mathrm{SiO}_{2}$, this can be due to decomposition of tromethamine salt [23], the final gradual loss from 200 to $500^{\circ} \mathrm{C}$ is attributable to the lost of structural $\mathrm{OH}$ groups from silica.

When we compared TGA in both water ratios, the main difference is that silica references initially loss more weight than those nanomaterials with ketorolac; this can be explained due to the time of aging in both samples, since drug-loaded silica required higher time than silica alone. Regarding to the water ratios, the difference due to the amount of water is barely noticeable.

3.2. TEM and EDS of Reservoirs. The surface morphology of the Ketorolac- $\mathrm{SiO}_{2}$ reservoirs was studied by transmission electron microscopy. The samples were placed on a cooper grid with a holey carbon support film. Several areas of the sample were photographed using the bright field technique (Figure 4), where the crystalline parts in Bragg orientation appear dark and the amorphous or not Bragg oriented parts appear bright [24], with a $200 \mathrm{kV}$ electron beam.

The micrographs showed aggregates formations of $\mathrm{SiO}_{2}$ in the drug-silica nanomaterial, with particle size of $20-$ $100 \mathrm{~nm}$ approximately; due to electrostatic forces between these particles, agglomeration occurs, giving rise to nanoparticles collection, similar to previously reported by Uddin et al. [25]. The images suggest no Ketorolac presence in the crystalline Silica formations surface, in comparison with the reference sample.

The EDS was obtained from different large groups of particles; several hundred nanometers wide showing and confirming the nanomaterial are silica pure not only in the surface, but also in the whole structure. The dispersive energy bands shown are purely from silicon and oxygen without any
TABLE 1: $\mathrm{N}_{2}$ adsorption parameters.

\begin{tabular}{lccc}
\hline Sample & $S_{\mathrm{BET}}\left(\mathrm{m}^{2} / \mathrm{g}\right)$ & $V_{P}\left(\mathrm{~cm}^{3} / \mathrm{g}\right)$ & $R_{p}(\mathrm{~nm})$ \\
\hline $\mathrm{SiO}_{2} 1: 4$ & 485 & 0.40 & 1.64 \\
$\mathrm{Ketorolac} \mathrm{SiO}_{2} 1: 4$ & 26 & 0.20 & 6.95 \\
$\mathrm{SiO}_{2} 1: 8$ & 532 & 0.26 & 1.64 \\
$\mathrm{Ketorolac} \mathrm{SiO}_{2} 1: 8$ & 95 & 0.60 & 1.64 \\
\hline
\end{tabular}

peak overlapping (Figure 6) with some peaks, in the case of the reference, due to the dispersive energy of the $\mathrm{Cu}$ grid (around 1, 8, and $9 \mathrm{keV}$ ) where the sample is sustained, and for that must be ignored.

\subsection{Surface Analysis Using Nitrogen Adsorption-Desorption.} $\mathrm{N}_{2}$ adsorption-desorption isotherms of the reservoirs measured at $77 \mathrm{~K}$ are shown in Figure 7; it can be clearly noticed that introducing Ketorolac modifies obtained isotherm. In both cases (1:8 and 1:4) ketorolac- $\mathrm{SiO}_{2}$ materials showed lower adsorption, because drug molecules fill the pores, blocking available space to nitrogen molecules to measure real surface area; this is confirmed by $S_{\mathrm{BET}}$ values (Table 1 ). Isotherm of the sample ketorolac- $\mathrm{SiO}_{2} 1: 8$ showed a type III according to IUPAC classification. In this case, ketorolac molecules showed weak interaction with nitrogen; thus adsorption of high amount of $\mathrm{N}_{2}$ is not achieved and no significant hysteresis was observed. The 1:4 ketorolac sample showed similar behavior although with a slight hysteresis, however as in reference sample, adsorbed volume is lower than 1:8 material, which means that when a larger ratio of water is used, higher porosity is obtained. In the references samples, isotherms are type IV. Microporosity of the samples can be confirmed by TEM images (Figures $4(\mathrm{~g})$ and 5(d)).

Pore size distributions showed a wide distribution for references; nevertheless we must consider the influence of adsorbed drug in pore occlusion, while in references we clearly observe a sharp peak around $2 \mathrm{~nm}$. These results are comparable with those reported by Guo et al. [26].

The BET surface area values observed in both references were between $620-800$ and both ketorolac- $\mathrm{SiO}_{2}$ samples exhibited less area values, confirming the presence of drug inside and over the surface of the material. Pore size distribution (PSD) was estimated from desorption branch using BJH method (Figure 8). In pure silica, when we used 1:8 ratio, a narrow distribution centered around $1.6 \mathrm{~nm}$ is observed, while in 1:4 ratio material, bimodal behavior with a second peak at $2.7 \mathrm{~nm}$ occurs. Incorporation of drug causes pore occlusion limiting adsorptive access and reducing $\mathrm{N}_{2}$ adsorption. In ketorolac $\mathrm{SiO}_{2} 1: 8$, a wide but small distribution from 14 to $22 \mathrm{~nm}$ (inset) can be observed, in the other sample $(1: 4)$ a minimal volume was adsorbed. These results are in agreement with observations made from corresponding isotherms.

3.4. In Vitro Drug Release. Several mathematical models are used to evaluate the kinetics of drug release from pharmacological formulations. The model that best fits the obtained data is selected based on the correlation coefficient $(r)$ value. 




(a)

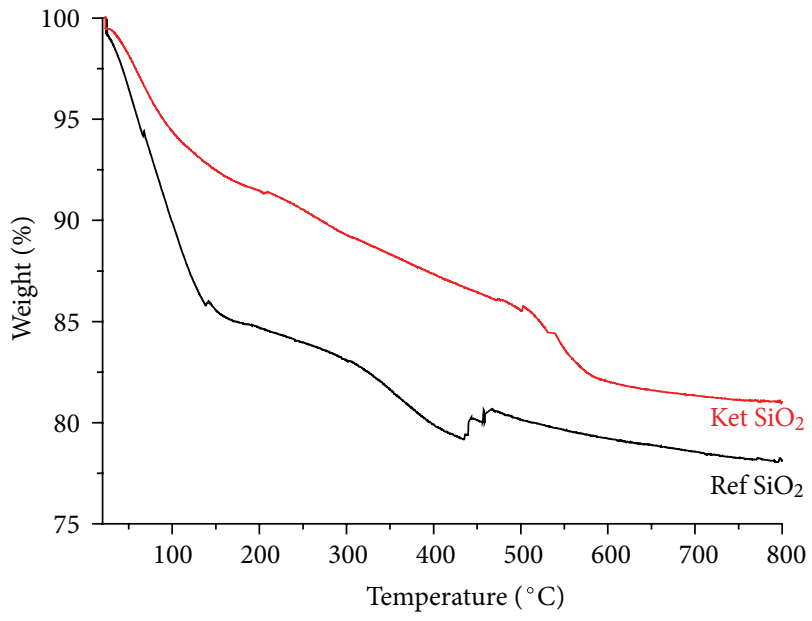

(b)

FIGURE 3: TGA curves of (a) 1:8 and (b) 1:4 samples.

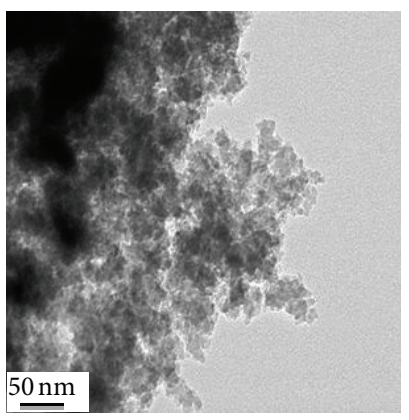

(a)



(e)

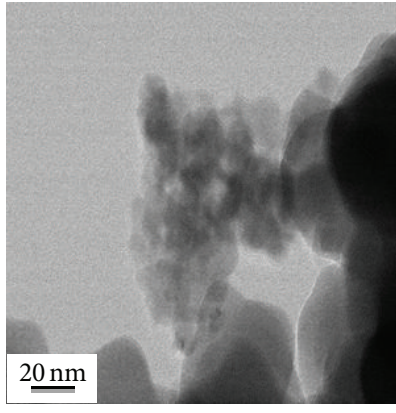

(b)

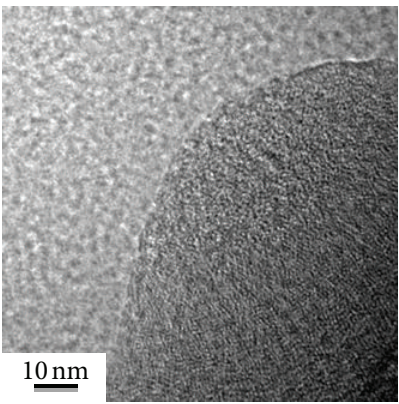

(f)

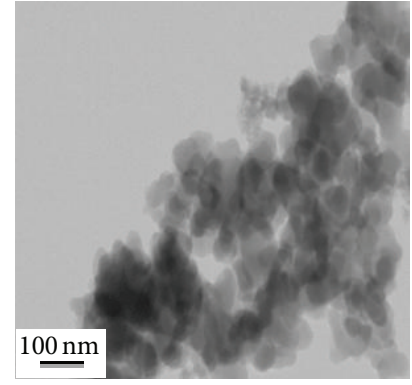

(c)

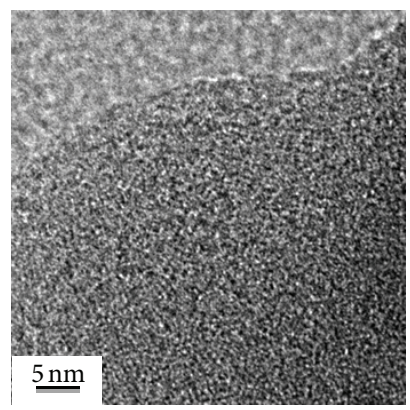

(g)

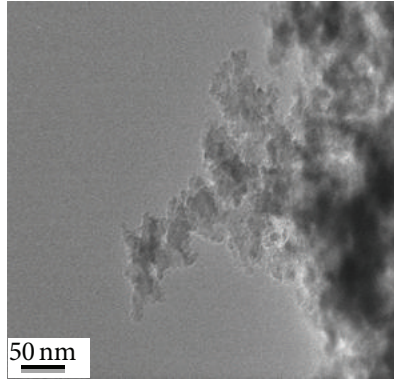

(d)

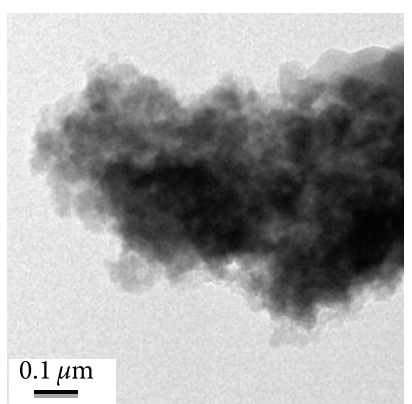

(h)

FIGURE 4: TEM images of ketorolac-SiO $21: 8$ in the first four images and of reference-SiO $1: 8$ in the next four images.

Several attempts have been made in order to avoid adverse side effects from oral administration of ketorolac, as the work of Genc and Jalvand [15] where they used hydrophilic matrix and achieved a slow release during 7 hours, another example is the use of microcapsules most of them made of Eudragit [27], and release the drug for no longer than 10 hours. Release profile of both Ketorolac-SiO ${ }_{2}$ samples is different from each other (Figure 9). The cumulative \% drug release from 1:4 was two times faster than 1:8 sample (Figure 10). This is probably due to more drug molecules being surface adsorbed in ketorolac $\mathrm{SiO}_{2} 1: 4$, and these are weakly bonded to the silica surface, releasing them more easily, and hence release time is shorter. For ketorolac $\mathrm{SiO}_{2}$ 1: 8 we observed that $90 \%$ of the drug was released after $200 \mathrm{hr}$. (Figure 9(a)).

In order to fit data to mathematical models, we applied five dissolution-diffusion kinetic models (zero-order, firstorder, Higuchi, Hixon-Crowell and hyperbola) and calculated the corresponding kinetic parameters and linear correlation coefficients $\left(R_{2}\right)$, these values are showed in Tables 2 and 3 . 


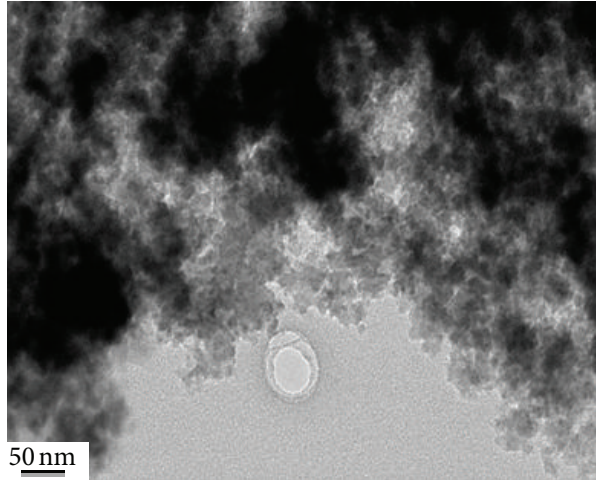

(a)

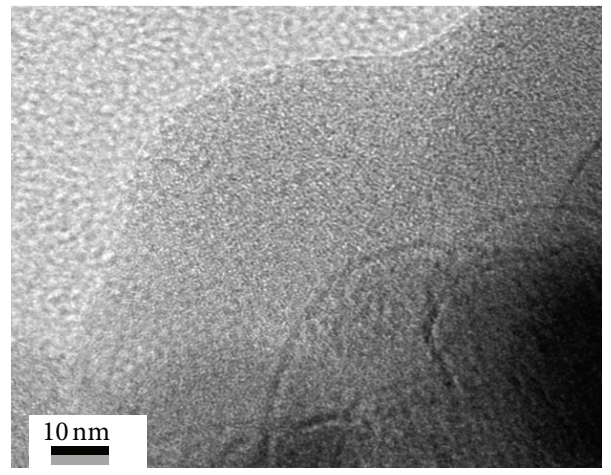

(c)



(b)

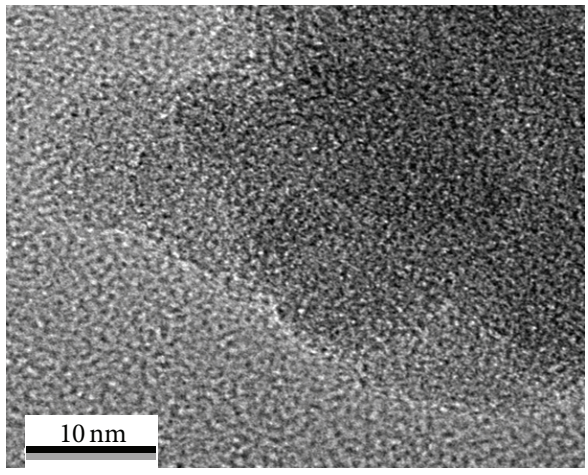

(d)

Figure 5: TEM images of 1:4 (a), (b) Ketorolac-SiO 2 and (c), (d) reference-SiO 2 .

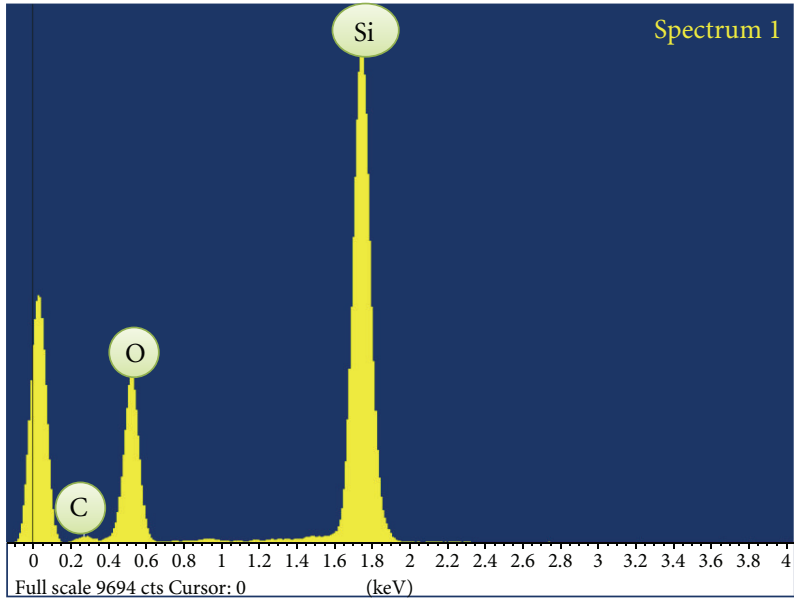

(a)

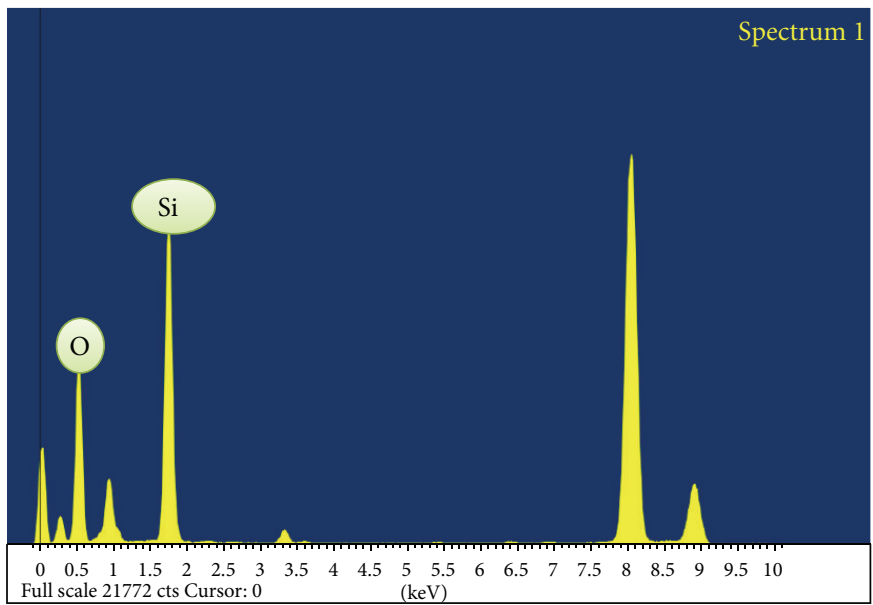

(b)

FIgure 6: EDS spectra of Ketorolac $\mathrm{SiO}_{2}$ 1:8 (a) and Reference $\mathrm{SiO}_{2}$ 1: 8 (b).

In general, the zero-order-first-order, Higuchi, and Hixon-Crowel models are not suitable to explain the controlled drug release data obtained in this study. The plots do not fit linear relationships and also have low correlation coefficients $\left(R_{2}<0.8\right)$. The hyperbola model fits the release data much better, with linear correlation coefficients of $R_{2}>$ 0.9 for both reservoirs; the rate of drug release shows a hyperbole not dependent on the concentration.
The difference in drug release is not only attributed to the presence of nanosized pores. The presence of a small amount of mesopores in the 1:4 material (in pure $\mathrm{SiO}_{2}$ ) implies that drug molecules can be occluded more easily in wider pores and release occurs faster than in micropores contributing to higher release rate. Also, during synthesis, considerable amount of adsorbed drug on particle surface might contribute to drug release in the initial phase. 
TABLE 2: Linearization coefficients obtained from in vitro release of Ketorolac from $\mathrm{SiO}_{2}$.

\begin{tabular}{|c|c|c|c|c|c|}
\hline Reservoir & $\begin{array}{c}\text { Zero-order } \\
Q_{t}=Q_{0}+K_{0} t\end{array}$ & $\begin{array}{c}\text { First-order } \\
Q_{t}=\ln Q_{0}-K_{1} t\end{array}$ & $\begin{array}{c}\text { Higuchi } \\
Q_{t}=k_{H} t^{1 / 2}\end{array}$ & $\begin{array}{c}\text { Hixon-crowel } \\
W_{0}^{1 / 3}-W_{t}^{1 / 3}=K_{s} t\end{array}$ & $\begin{array}{c}\text { Hyperbola } \\
a * x /(b+x)\end{array}$ \\
\hline Ketorolac $\mathrm{SiO}_{2} 1: 8$ & 0.4183 & 0.6809 & 0.5980 & 0.5712 & 0.9651 \\
\hline Ketorolac $\mathrm{SiO}_{2} 1: 4$ & 0.7496 & 0.9664 & 0.8644 & 0.8919 & 0.9516 \\
\hline
\end{tabular}

$Q_{t}$ : amount of drug released in time $t$.

$\mathrm{Q}_{0}$ : initial amount of drug in the tablet.

$K_{0}, K_{1}, k_{H}, K_{s}:$ release rate constants.

$b$ : shape parameter.

a: scale parameter.

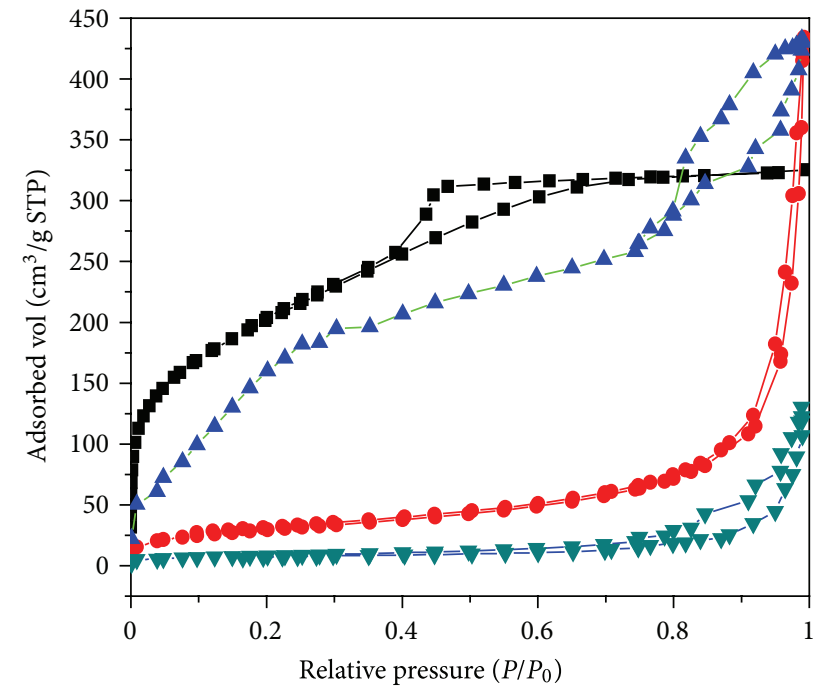

FIGURE 7: Nitrogen adsorption-desorption isotherms for the reservoirs at different stoichiometric relation as follows: $(-\square-)$ reference$\mathrm{SiO}_{2} 1: 8,(-\bullet-)$ ketorolac-SiO${ }_{2} 1: 8,(-\boldsymbol{\Delta}-)$ Reference $\mathrm{SiO}_{2} 1: 4$, and $(-\nabla-)$ Ketorolac $\mathrm{SiO}_{2} 1: 4$.

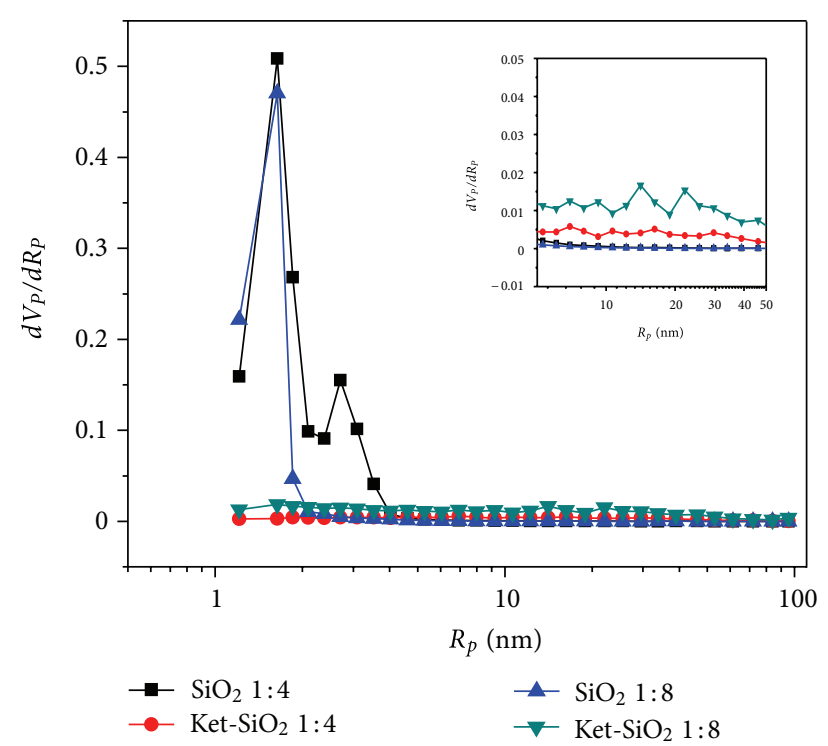

Figure 8: Pore size distribution of the $\mathrm{SiO}_{2}$ materials.

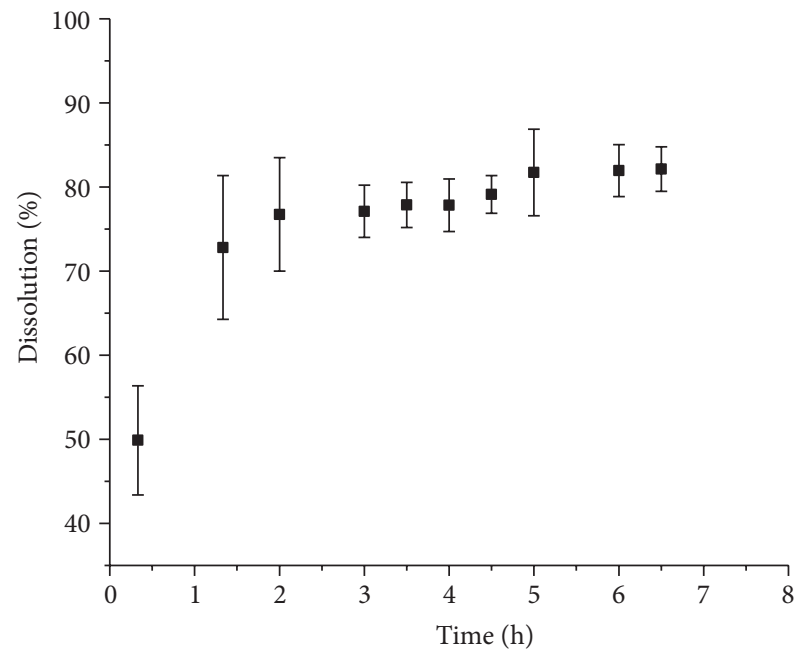

(a)

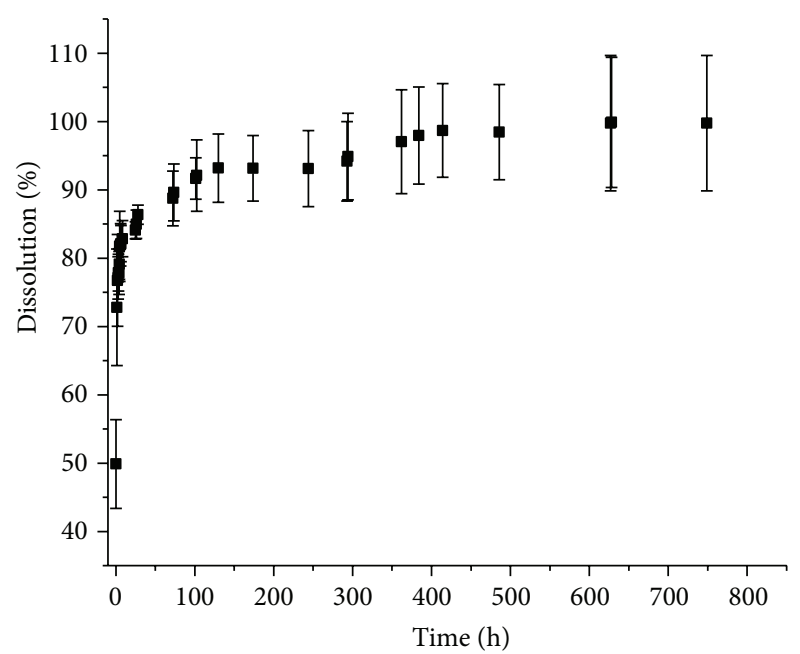

(b)

FIGURE 9: In vitro release profile of ketorolac from $\mathrm{SiO}_{2} 1: 8$ reservoir (a) first 8 hours and (b) full time.

\section{Conclusion}

The development of new pharmaceutical formulations to enhance the therapeutic effect of conventional drugs is a rising area. Most micro- and nanomaterial used for this purposes are organic polymers; however since most of them 


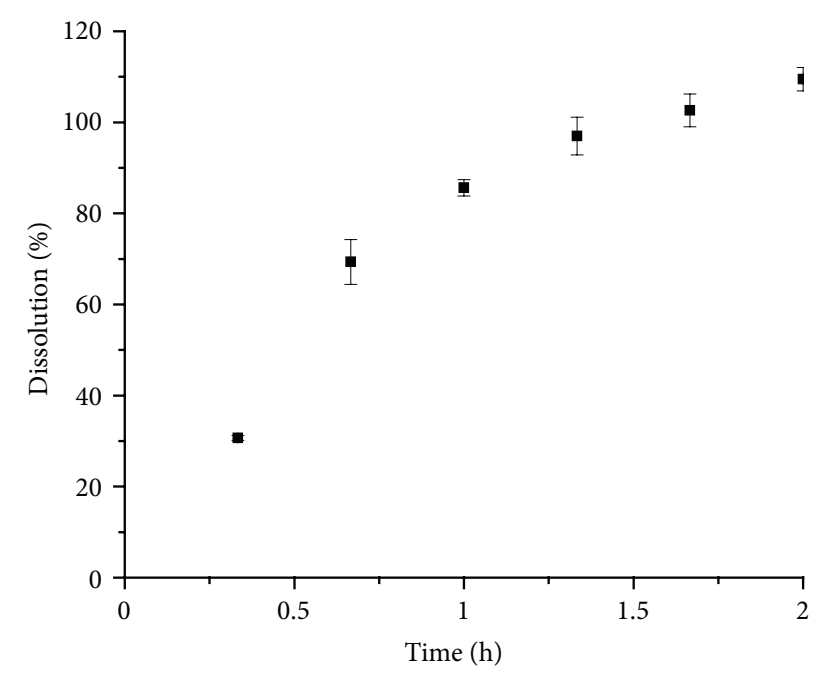

Figure 10: Release profile from $\mathrm{SiO}_{2} 1: 4$.

TABLE 3: Drug release rates calculated for the different mathematical models.

\begin{tabular}{lcc}
\hline Mathematical model & Ketorolac $\mathrm{SiO}_{2} 1: 4$ & Ketorolac $\mathrm{SiO}_{2} 1: 8$ \\
\hline Zero-order [\%/h] & 30.51 & 0.09563 \\
First-order [h] & 3.057 & 0.00677 \\
Higuchi $[\%]$ & 72.97 & 1.69 \\
Hixon-Crowell $\left[\mathrm{h}^{-1}\right]$ & 0.5364 & 0.0081 \\
Hyperbola $[\% / \mathrm{h}]$ & 176.62 & 88.01 \\
\hline
\end{tabular}

are commercially available, less control over their physical and chemical properties can be achieved. In order to bypass their limitations, alternative nanostructured materials like silica can be used. We synthesized silica nanoparticles with ketorolac for drug release. The best molar ratio was $1: 8$, since $80 \%$ of the drug is released at the 10 hours with a slower rate in the following hours reaching the $90 \%$ at the end of the time. Although 1:4 material released much faster, the behavior of 1:8 material was more homogeneous. Both systems represent an alternative to deliver ketorolac in a more controlled way. Sol-gel process is a potential method to obtain designed materials with suitable characteristics to host a great variety of molecules.

\section{Acknowledgments}

The authors would like thank to Universidad Autónoma Metropolitana and National Institute of Neurology an Neurosurgery for facilities; special thanks to P. Castillo for TEM studies also Project FONCICYT-CONACYT 96095 for financial support.

\section{References}

[1] R. Bawa, "Patents and nanomedicine," Nanomedicine, vol. 2, no. 3, pp. 351-374, 2007.
[2] R. Bawa, S. R. Bawa, S. B. Maebius, T. Flynn, and C. Wei, "Protecting new ideas and inventions in nanomedicine with patents," Nanomedicine, vol. 1, no. 2, pp. 150-158, 2005.

[3] A. Abdulwahed, "Gastrointestinal and cardiovascular risk of nonsteroidal anti-inflammatory drugs," Oman Medical Journal, vol. 26, no. 6, pp. 385-391, 2011.

[4] L. Filaretova, T. Bagaeva, O. Morozova, and D. Zelena, "The healing of nsaid-induced gastric lesion may be followed by small intestinal and cardiovascular side effects," Journal of Physiology and Pharmacology, vol. 62, no. 6, pp. 619-625, 2011.

[5] I. Pountos, T. Georgouli, G. Calori, and P. Giannoudis, "Do nonsteroidal anti-inflammatory drugs affect bone healing?" The Scientific World Journal, vol. 2012, Article ID 606404, 14 pages, 2012.

[6] N. M. Gajraj, "The effect of cyclooxygenase-2 inhibitors on bone healing," Regional Anesthesia and Pain Medicine, vol. 28, no. 5, pp. 456-465, 2003.

[7] L. E. Targownik, C. J. Metge, S. Leung, and D. G. Chateau, "The relative efficacies of gastroprotective strategies in chronic users of nonsteroidal anti-inflammatory drugs," Gastroenterology, vol. 134, no. 4, pp. 937-e1, 2008.

[8] J. Varshosaz, V. Hajhashemi, and S. Soltanzadeh, "Lipid nanocapsule-based gels for enhancement of transdermal delivery of ketorolac tromethamine," Journal Drug Delivery, vol. 2011, Article ID 571272, 7 pages, 2011.

[9] P. Santhosh, N. Senthil Kumar, M. Renukadevi, A. I. Gopalan, T. Vasudevan, and K. P. Lee, "Enhanced electrochemical detection of ketorolac tromethamine at polypyrrole modified glassy carbon electrode," Analytical Sciences, vol. 23, no. 4, pp. 475478, 2007.

[10] S. Hungund and R. Thakkar, "Effect of pretreatment with Ketorolac Tromethamine on operative pain during periodontal surgery: a case-control study," Journal of Indian Society of Periodontology, vol. 15, no. 1, pp. 55-58, 2011.

[11] S. K. Paliwal, R. Chauhan, V. Sharma, D. K. Majumdar, and S. Paliwal, "Entrapment of ketorolac tromethamine in polymeric vehicle for controlled drug delivery," Indian Journal of Pharmaceutical Sciences, vol. 71, no. 6, pp. 687-691, 2009.

[12] M. A. Radwan, B. T. AlQuadeib, N. M. Aloudah, and H. Y. Aboul Enein, "Pharmacokinetics of ketorolac loaded to polyethylcyanoacrylate nanoparticles using UPLC MS/MS for its determination in rats," International Journal of Pharmaceutics, vol. 397, no. 1-2, pp. 173-178, 2010.

[13] V. R. Sinha and A. Trehan, "Formulation, characterization, and evaluation of ketorolac tromethamine-loaded biodegradable microspheres," Drug Delivery, vol. 12, no. 3, pp. 133-139, 2005.

[14] A. P. Rokhade, S. A. Agnihotri, S. A. Patil, N. N. Mallikarjuna, P. V. Kulkarni, and T. M. Aminabhavi, "Semi-interpenetrating polymer network microspheres of gelatin and sodium carboxymethyl cellulose for controlled release of ketorolac tromethamine," Carbohydrate Polymers, vol. 65, no. 3, pp. 243-252, 2006.

[15] L. Genc and E. Jalvand, "Preparation and in vitro evaluation of controlled release hydrophilic matrix tablets of ketorolac tromethamine using factorial design," Drug Development and Industrial Pharmacy, vol. 34, no. 8, pp. 903-910, 2008.

[16] T. López, S. Recillas, P. Guevara, J. Sotelo, M. Alvarez, and J. A. Odriozola, "Pt/TiO2 brain biocompatible nanoparticles: GBM treatment using the C6 model in Wistar rats," Acta Biomaterialia, vol. 4, no. 6, pp. 2037-2044, 2008. 
[17] K. Farrington and F. Regan, "Molecularly imprinted sol gel for ibuprofen: an analytical study of the factors influencing selectivity," Talanta, vol. 78, no. 3, pp. 653-659, 2009.

[18] J. Gonzáles, J. Pérez, F. Ruiz, and J. y Martínez, "Vidrios $\mathrm{SiO}_{2}$ nanocompuestos preparados por sol-gel: revisión," Superficies y Vacío, vol. 11, pp. 1-16, 2000.

[19] J. Livage, C. Sanchez, M. Henry, and S. Doeuff, "The chemistry of the sol-gel process," Solid State Ionics, vol. 32-33, no. 2, pp. 633-638, 1989.

[20] J. Livage, "Sol-gel processes," Current Opinion in Solid State and Materials Science, vol. 2, no. 2, pp. 132-138, 1997.

[21] A. Kalampounias, "IR and Raman spectroscopic studies of solgel derived alkaline-earth silicate glasses," Bulletin of Materials Science, vol. 34, no. 2, pp. 299-303, 2011.

[22] C. M. Whang, C. S. Yeo, and Y. H. Kim, "Preparation and characterization of sol-gel derived $\mathrm{SiO}_{2}-\mathrm{TiO}_{2}$-PDMS composite films," Bulletin of the Korean Chemical Society, vol. 22, no. 12, pp. 1366-1370, 2001.

[23] Y. T. Sohn and O. S. Hyun, "Crystal forms of ketorolac," Archives of Pharmacal Research, vol. 27, no. 3, pp. 357-360, 2004.

[24] W. Lin and Zhong, Characterization of Nanophase Materials, Transmission Electron Microscopy and Spectroscopy of Nanoparticles, Qilwy-VCH Verlag GmbH, Berlin, Germany, 2000.

[25] M. J. Uddin, D. Mondal, C. A. Morris, T. Lopez, U. Diebold, and R. D. Gonzalez, "An in vitro controlled release study of valproic acid encapsulated in a titania ceramic matrix," Applied Surface Science, vol. 257, no. 18, pp. 7920-7927, 2011.

[26] H. Guo, H. Qian, S. Sun et al., "Hollow mesoporous silica nanoparticles for intracellular delivery of fluorescent dye," Chemistry Central Journal, vol. 5, no. 1, p. 1, 2011.

[27] K. Ruckmani, M. S. Muneera, and R. Vijaya, "Eudragit matrices for sustained release of ketorolac tromethamine: formulation and kinetics of release," Bollettino Chimico Farmaceutico, vol. 139, no. 5, pp. 205-208, 2000. 

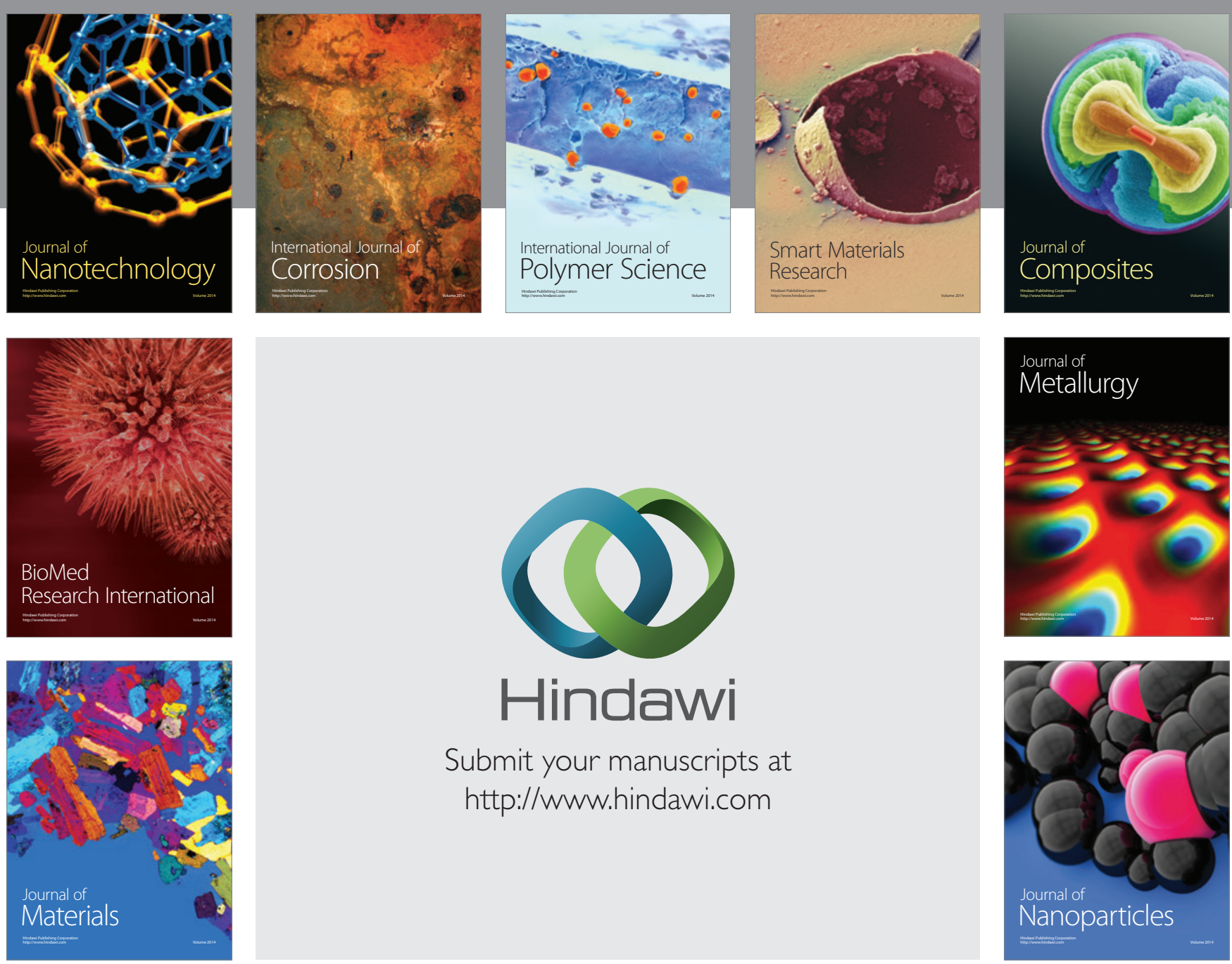

Submit your manuscripts at http://www.hindawi.com
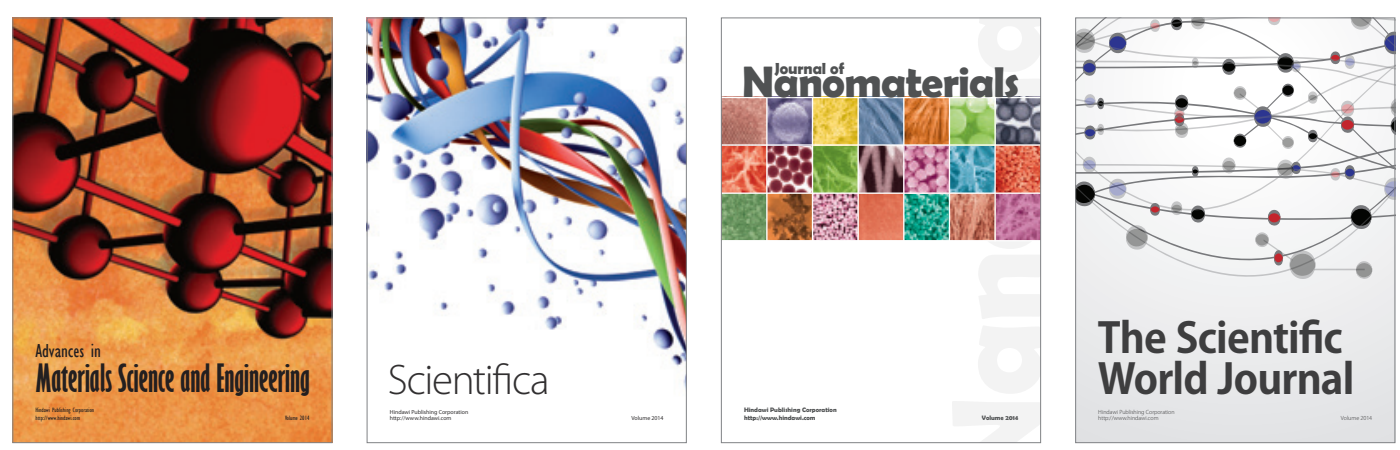

\section{The Scientific World Journal}
